\title{
Adaptive Synchronization of Fractional-Order Complex-Valued Chaotic Neural Networks with Time-Delay and Unknown Parameters
}

\author{
Mei Li ${ }^{1,2}$, Ruoxun Zhang ${ }^{3}$ and Shiping Yang ${ }^{2, *}$ \\ 1 College of Physics, Hebei Normal University, Shijiazhuang 050024, China; limeijsj@ncepu.edu.cn \\ 2 Department of Computer Science, North China Electric Power University, Baoding 071003, China \\ 3 College of Physics and Electronic Engineering, Xingtai University, Xingtai 054001, China; \\ 199010086@xttc.edu.cn \\ * Correspondence: yangship@hebtu.edu.cn; Tel.: +86-132-921-67929
}

Citation: Li, M.; Zhang, R.; Yang, S. Adaptive Synchronization of Fractional-Order Complex-Valued Chaotic Neural Networks with Time-Delay and Unknown Parameters. Physics 2021, 3, 924-939. https://doi.org/10.3390/ physics3040058

Received: 2 August 2021

Accepted: 30 September 2021

Published: 12 October 2021

Publisher's Note: MDPI stays neutral with regard to jurisdictional claims in published maps and institutional affiliations.

Copyright: (c) 2021 by the authors. Licensee MDPI, Basel, Switzerland. This article is an open access article distributed under the terms and conditions of the Creative Commons Attribution (CC BY) license (https:// creativecommons.org/licenses/by/ $4.0 /)$.

\begin{abstract}
The purpose of this paper is to study and analyze the concept of fractional-order complexvalued chaotic networks with external bounded disturbances and uncertainties. The synchronization problem and parameter identification of fractional-order complex-valued chaotic neural networks (FOCVCNNs) with time-delay and unknown parameters are investigated. Synchronization between a driving FOCVCNN and a response FOCVCNN, as well as the identification of unknown parameters are implemented. Based on fractional complex-valued inequalities and stability theory of fractionalorder chaotic complex-valued systems, the paper designs suitable adaptive controllers and complex update laws. Moreover, it scientifically estimates the uncertainties and external disturbances to establish the stability of controlled systems. The computer simulation results verify the correctness of the proposed method. Not only a new method for analyzing FOCVCNNs with time-delay and unknown complex parameters is provided, but also a sensitive decrease of the computational and analytical complexity.
\end{abstract}

Keywords: adaptive synchronization; fractional-order; complex-valued chaotic neural networks; time-delay; unknown complex parameter

\section{Introduction}

Compared with real-valued neural networks, complex-valued neural networks have the advantages of simpler network structure, simpler training process, and stronger ability to handle complex signals. This is mainly due to the fact that the state vectors, connection weights, and activation functions in complex-valued neural networks are all represented by complex values. In addition, complex-valued neural networks can solve problems that cannot be solved by real-valued neural networks. For example, two-layer real-valued neural networks cannot solve the problems of exclusive "OR" (XOR) and symmetry detection, while two-layer complex-valued neural networks can easily do so, which shows that the computational ability of complex-valued neurons is remarkable. In recent years, practical applications of complex-valued neural networks in physical systems such as electromagnetic, optical, ultrasonic, and quantum waves, as well as in the fields of filtering, speech synthesis, and remote sensing, have attracted widespread attention [1-19].

With the development of fractional calculus, more and more researchers recognize that fractional-order models can better describe various substances and processes with memory and genetic properties in neural networks than integer-order models, and can also effectively facilitate the information process. Meanwhile, fractional-order calculus in neural networks can improve the accuracy and flexibility of computation, and have a great application value in computational optimization and control performance improvement. Therefore, combining fractional-order calculus with neural network models to 
form fractional-order neural network models expands the basic theory and application capabilities of neural networks.

The analysis of fractional-order neural networks (FNNs) has become a research area attracting increasing interest (see [20-40] and references therein). Moreover, the simultaneous analysis of stability of fractional-order real-valued and complex-valued neural networks has received extensive attention. In $[20,21]$, projection synchronization and adaptive synchronization of fractional-order memristor neural networks are discussed. In [10], synchronization of fractional-order complex-valued neural networks (FOCVNNs) was studied using the linear delay feedback control. The authors investigated the global Mittag-Leffler synchronization problem of fractional-order neural networks in Refs. [22-24]. In Refs. [25-32], the authors analyzed the stability, finite-time stability, and global MittagLeffler stability of fractional-order time-delayed complex-valued neural networks, respectively. In [31], several sufficient conditions for achieving finite-time projection synchronization of fractional-order complex-valued neural networks are derived by applying set-valued mappings, differential inclusion theory, and Gronwalls' inequality. In [32], Li et al. implemented the adaptive synchronization of fractional-order complex-valued neural networks with discrete and distributed delays. The modified function projective synchronization (MFPS) for complex dynamical networks with mixed time-varying and hybrid asymmetric coupling delays was investigated in [33]. In [34], the authors studied a novel delay-dependent asymptotic stability of a differential and Riemann-Liouville fractional differential neutral system with constant delays and nonlinear perturbation. In [35], Dai et al. reported that in populations with cooperative and competitive oscillators, the transition between continuous and explosive can be tuned simply by adjusting the balance between the two oscillator types. Furthermore, Dai et al. [36] proposed a unified framework for the analysis of system synchronization and conducted an in-depth study of network synchronization laws in different dimensions.

It should be noted that the aforementioned papers on neural network synchronization all assume that the network is predetermined. In fact, in many practical engineering situations, most system parameters cannot be accurately determined in advance, and chaotic synchronization will be disrupted by these uncertainties. In addition, there are usually delays in neural networks due to the limited speed of signal transmission between neurons. Time-delay can have an impact on the dynamic properties of a neural network and can even destroy it. Although, authors in [37] investigated the controller design problem for finite-time and fixed-time stabilization of fractional-order memristive complex-valued bidirectional associative memory (BAM) neural networks with uncertain parameters and time-varying delays, but the nonlinear complex-valued activation functions are split into two (real and imaginary) components. Therefore, to the best of our knowledge, there are few studies on the synchronization of fractional-order complex-valued chaotic neural networks (FOCVCNNs) with time-delays and unknown parameters, especially without dividing the real and imaginary components into two real-valued systems. Therefore, it is very important and useful to efficiently synchronize fractional-order complex-valued chaotic neural networks with time-delays and unknown parameters in practical applications.

Inspired by the above discussion, this paper investigates the synchronization problem of FOCVCNNs with time-delay and unknown complex parameters. Using inequalities containing fractional-order derivatives of complex variables and the stability theory of fractional-order complex-valued chaotic systems, synchronization and parameter identification of FOCVCNNs are achieved.

The main contributions of this paper can be summarized as follows.

(i) Most of the existing studies on the synchronization methods of fractional-order neural networks are about fractional-order real-valued neural networks. On the other hand, existing studies on fractional-order complex-valued neural networks are on the known parameters or with no time-delay or without identifying the parameters. 
(ii) A new adaptive controller and update laws are designed to synchronize the driving and response systems. This is the first study of synchronization of fractional-order complex-valued neural networks with time-delay and unknown complex parameters.

(iii) Compared with previous synchronization models of fractional-order complex neural networks, the model proposed in this paper is more tractable and easier to be implemented in practical systems.

(iv) For fractional-order complex neural networks with known parameters and time-delay or known parameters without time-delay, the synchronization model proposed in this paper is also applicable, and only the control strategies need to be adjusted accordingly.

(v) This paper proposes the novel perspective that chaos occurs in fractional-order complex-valued neural networks as long as the parameters are suitable, and two new FOCVCNNs are given to broaden the application of fractional-order complex-valued neural networks.

\section{Preliminaries}

Fractional calculus plays an important role in modern science. In this paper, RiemannLiouville and Caputo's fractional operators are used as the main tools.

Notation: $\mathbb{C}^{n}$ denotes a complex $n$-dimensional space. For $z \in \mathbb{C}, \operatorname{Re}(z), \operatorname{Im}(z)$ and $\bar{z}$ are the real part, imaginary part, and conjugate of $z$, respectively.

Definition 1 ([41]). The fractional integral form of order $\alpha$ for function $f$ is defined as follows:

$$
I^{\alpha} f(t)={ }_{t_{0}} D_{t}^{-\alpha} f(t)=\frac{1}{\Gamma(\alpha)} \int_{t_{0}}^{t}(t-\tau)^{\alpha-1} f(\tau) d \tau,
$$

where $t$ denotes the time and $t_{0}$ is the initial time, $t \geq t_{0}$, and $\alpha>0$.

Definition 2 ([41]). Caputo's fractional derivative form of order $\alpha$ for function $f \in \mathbb{R}^{n}$ is defined by:

$$
{ }_{t_{0}}^{C} D_{t}^{\alpha} f(t)=\frac{1}{\Gamma(n-\alpha)} \int_{t_{0}}^{t} \frac{f^{(n)}(\tau)}{(t-\tau)^{\alpha-n+1}} d \tau,
$$

where $t \geq t_{0}$ and $n$ are a positive integer, then $n-1<\alpha<1$.

Lemma 1. Let $z$ be a differentiable complex-valued function. Then, $\forall t \geq t_{0}$ and $\alpha \in(0,1]$, and the following inequality holds [42]:

$$
{ }_{t_{0}}^{C} D_{t}^{\alpha} \overline{z(t)} z(t) \leq \overline{z(t)}{ }_{t_{0}}^{C} D_{t}^{\alpha} z(t)+\left({ }_{t_{0}}^{C} D_{t}^{\alpha} \overline{z(t)}\right) z(t) .
$$

Lemma 2. (Stability theory for fractional-order system [41]). Let $V_{1}(t)$ be a uniformly continuous and derivable Lyapunov function, and let $V_{2}(t)$ be a derivable and nonnegative function.

$$
\text { If }
$$

$$
V(t)=V_{1}(t)+V_{2}(t),
$$

and

$$
{ }_{0}^{C} D_{t}^{\alpha} V(t) \leq-\theta V_{1}(t),
$$

where $\theta$ is a positive constant. Then, $\lim _{t \rightarrow \infty} V_{1}(t)=0$.

Lemma 3 ([43]). Let $V(t)$ and $U(t)$ be two nonnegative continuous functions, and satisfy

$$
{ }_{0}^{C} D_{t}^{\alpha}(V(t)+U(t)) \leq-\sigma V(t)+\rho,
$$


where $0<\alpha<1, \sigma<0$, and $\rho>0$, then

$$
V(t) \leq\left(V(0)+U(0)-\frac{\rho}{\sigma}\right) E_{a, 1}\left(-\sigma t^{\alpha}\right)+\frac{\rho}{\sigma} .
$$

Remark 1. Since $E_{\alpha, 1}\left(-\sigma t^{\alpha}\right) \rightarrow 0(\sigma>0)$, as $t \rightarrow \infty$, if $\rho=0$, one can deduce Lemma 2 , by this Lemma.

Lemma 4 ([44]). For any $\alpha, \beta \in \mathbb{C}$, and any $\delta>0$, the following inequality holds:

$$
\alpha \bar{\beta}+\bar{\alpha} \beta \leq \delta \alpha \bar{\alpha}+\frac{1}{\delta} \beta \bar{\beta} .
$$

\section{Main Results}

Let us consider a kind of FOCVCNNs described by the following equations:

$$
\left\{\begin{array}{l}
{ }_{0}^{C} D_{t}^{\alpha} z_{i}(t)=-c_{i} z_{i}(t)+\sum_{j=1}^{n} a_{i j} f_{j}\left(z_{j}(t)\right)+\sum_{j=1}^{n} b_{i j} g_{j}\left(z_{j}(t-\tau)\right)+I_{i}(t), t \geq 0, i=1,2, \cdots, n, \\
z_{i}(s)=\varphi_{i}(s), s \in[-\tau, 0],
\end{array}\right.
$$

where $0<\alpha<1$, and $z_{i}(t) \in \mathbb{C}$ is the complex state variable of the $i$ th neuron; $f_{j}(\cdot)$, $g_{j}(\cdot) \in \mathbb{C}$ represent the activation functions without and with delay; $a_{i j}, b_{i j} \in \mathbb{C}$ denote the connection weight and delayed connection weight, respectively; $c_{i} \in \mathbb{R}, \tau>0$ are constant delays; and $I_{i}$ represents the corresponding external inputs. The complex-valued functions $f_{j}(\cdot), g_{j}(\cdot)$ and $I_{i}$ satisfy the following assumptions.

Assumption 1. For any $\mu, v \in \mathbb{C}$, there exist real numbers $l_{j}, h_{j}>0$, then

$$
\left|f_{j}(\mu)-f_{j}(v)\right| \leq l_{j}|\mu-v|,\left|g_{j}(\mu)-g_{j}(v)\right| \leq h_{j}|\mu-v| .
$$

Assumption 2. For any $v \in \mathbb{C}$, there exist real numbers $\gamma_{i}>0$ and $\varepsilon_{i}>0$, then

$$
\left|f_{j}(v)\right| \leq \gamma_{i},\left|I_{i}(v)\right| \leq \varepsilon_{i} .
$$

Choose system (9) as the master system, and $a_{i j}, b_{i j}$ are unknown constants which need to be identified, then the controlled response system is given by:

$$
\left\{\begin{array}{l}
{ }_{0}^{C} D_{t}^{\alpha} \boldsymbol{w}_{i}(t)=-c_{i} \boldsymbol{w}_{i}(t)+\sum_{j=1}^{n} \alpha_{i j} f_{j}\left(\boldsymbol{w}_{j}(t)\right)+\sum_{j=1}^{n} \beta_{i j} g_{j}\left(\boldsymbol{w}_{j}(t-\tau)\right)+I_{i}(t)+u_{i}(t), \quad t \geq 0, i=1,2, \cdots, n, \\
w_{i}(s)=\varphi_{i}(s), s \in[-\tau, 0],
\end{array}\right.
$$

where $w_{i}(t) \in \mathbb{C}$ is the complex state variable of the $i$ th neuron of the response system; $\alpha_{i j}, \beta_{i j} \in \mathbb{C}$ represent the estimated connection weights and delayed connection weights, respectively; and $u(t)=\left(u_{1}(t), u_{2}(t), \cdots, u_{n}(t)\right)^{T}$ are controllers to be determined.

Let $e_{i}(t)=w_{i}(t)-z_{i}(t)$ be the synchronization errors between master system (9) and slave system (12), then one can get the following error dynamical system:

$$
\begin{aligned}
&{ }_{0}^{C} D_{t}^{\alpha} \boldsymbol{e}_{i}(t)=-c_{i} \boldsymbol{e}_{i}(t)+ \\
&=-\sum_{j=1}^{n}\left[\alpha_{i j} f_{j}\left(\boldsymbol{w}_{j}(t)\right)+\sum_{j=1}^{n}\left\{a_{i j}\left[f_{j}\left(\boldsymbol{w}_{j}(t)\right)-f_{j}\left(\boldsymbol{z}_{j}(t)\right)\right]+\left(\boldsymbol{z}_{j}(t)\right)\right]+\sum_{j=1}^{n}\left[\beta_{i j} g_{j}\left(\boldsymbol{w}_{j}(t) f_{j}\left(\boldsymbol{w}_{j}(t)\right)\right\}\right.\right. \\
& \\
& \quad+\sum_{j=1}^{n}\left\{b_{i j}\left[g_{j}\left(\boldsymbol{w}_{j}(t-\tau)\right)-g_{j}\left(\boldsymbol{z}_{j}(t-\tau)\right)\right]+\left(\beta_{i j}-b_{i j}\right) g_{j}\left(\boldsymbol{w}_{j}(t-\tau)\right)\right\}+u_{j}(t) .
\end{aligned}
$$


Theorem 1. If Assumptions 1 and 2 hold, the asymptotic synchronization and parameter identification of systems (9) and (12) can be achieved under adaptive controllers, described as Equation (14) and adaptive update laws (15)-(18):

$$
\begin{gathered}
u_{i}(t)=-k_{i}(t) e_{i}(t)-m_{i} \frac{e_{i}(t)}{\overline{e_{i}(t)}} \overline{e_{i}(t)} \overline{e_{i}(t-\tau)} e_{i}(t-\tau), i=1,2, \cdots, n, \\
{ }_{0}^{C} D_{t}^{\alpha} k_{i}=\sigma_{i} \overline{e_{i}(t)} e_{i}(t), \\
{ }_{0}^{C} D_{t}^{\alpha} m_{i}=\varepsilon_{i} \overline{e_{i}(t-\tau)} e_{i}(t-\tau), \\
{ }_{0}^{C} D_{t}^{\alpha} \alpha_{i j}=-\eta_{i} \bar{j} \overline{f_{j}\left(w_{j}(t)\right)} e_{i}(t), \\
{ }_{0}^{C} D_{t}^{\alpha} \beta_{i j}=-\xi_{i} \bar{j} \overline{g_{j}\left(w_{j}(t-\tau)\right)} e_{i}(t),
\end{gathered}
$$

where $\sigma_{i}, \varepsilon_{i}, \eta_{i} j, \xi_{i}$ are positive constants.

Proof. Let us present the following Lyapunov functional candidate:

$$
\begin{aligned}
V_{1}(t)= & \sum_{i=1}^{n} \bar{e}_{i}(t) e_{i}(t)=e^{H}(t) e(t), \\
V_{2}(t)= & \sum_{i=1}^{n}\left[\frac{1}{\sigma_{i}}\left(k_{i}-k_{i}^{*}\right)^{2}+\frac{1}{\varepsilon_{i}}\left(m_{i}-m_{i}^{*}\right)^{2}\right. \\
& \left.+\sum_{j=1}^{n} \frac{1}{\eta_{i j}}\left(\bar{\alpha}_{i j}-\bar{a}_{i j}\right)\left(\alpha_{i j}-a_{i j}\right)+\sum_{j=1}^{n} \frac{1}{\eta_{i j}}\left(\bar{\beta}_{i j}-\bar{b}_{i j}\right)\left(\beta_{i j}-b_{i j}\right)\right],
\end{aligned}
$$

where $k_{i}{ }^{*}, m_{i}{ }^{*}$ are two positive constants to be determined.

\section{Using Lemma 1:}

$$
\begin{aligned}
{ }_{0}^{C} D_{t}^{\alpha}\left(V_{1}(t)+V_{2}(t)\right)= & { }_{0}^{C} D_{t}^{\alpha} \sum_{i=1}^{n} \bar{e}_{i}(t) e_{i}(t)+{ }_{0}^{C} D_{t}^{\alpha} \sum_{i=1}^{n}\left[\frac{1}{\sigma_{i}}\left(k_{i}-k_{i}^{*}\right)^{2}+\frac{1}{\varepsilon_{i}}\left(m_{i}-m_{i}^{*}\right)^{2}\right. \\
& \left.+\sum_{j=1}^{n} \frac{1}{\eta_{i j}}\left(\bar{\alpha}_{i j}-\bar{a}_{i j}\right)\left(\alpha_{i j}-a_{i j}\right)+\sum_{j=1}^{n} \frac{1}{\eta_{i j}}\left(\bar{\beta}_{i j}-\bar{b}_{i j}\right)\left(\beta_{i j}-b_{i j}\right)\right] \\
\leq & \sum_{i=1}^{n} \bar{e}_{i}(t)_{0}^{C} D_{t}^{\alpha} e_{i}(t)+\sum_{i=1}^{n} e_{i}(t)_{0}^{C} D_{t}^{\alpha} e_{i}(t) \\
& +\sum_{i=1}^{n}\left[\frac{2}{\sigma_{i}}\left(k_{i}-k_{i}^{*}\right)_{0}^{C} D_{t}^{\alpha} k_{i}+\frac{2}{\varepsilon_{i}}\left(m_{i}-m_{i}^{*}\right)_{0}^{C} D_{t}^{\alpha} m_{i}\right. \\
& +\sum_{j=1}^{n} \frac{1}{\eta_{i j}}\left(\bar{\alpha}_{i j}-\bar{a}_{i j}\right)_{0}^{C} D_{t}^{\alpha}\left(\alpha_{i j}-a_{i j}\right)+\sum_{j=1}^{n} \frac{1}{\eta_{i j}}\left(\bar{\alpha}_{i j}-a_{i j}\right)_{0}^{C} D_{t}^{\alpha}\left(\alpha_{i j}-a_{i j}\right) \\
& \left.+\sum_{j=1}^{n} \frac{1}{\eta_{i j}}\left(\bar{\beta}_{i j}-\bar{b}_{i j}\right)_{0}^{C} D_{t}^{\alpha}\left(\beta_{i j}-b_{i j}\right)+\sum_{j=1}^{n} \frac{1}{\eta_{i j}}\left(\bar{\beta}_{i j}-b_{i j}\right)_{0}^{C} D_{t}^{\alpha}\left(\beta_{i j}-b_{i j}\right)\right] .
\end{aligned}
$$

Along with Equation (13) and qualities (14)-(18), one gets:

$$
\begin{aligned}
{ }_{0}^{C} D_{t}^{\alpha}\left(V_{1}(t)+V_{2}(t)\right) \leq & -\sum_{i=1}^{n} 2 \bar{e}_{i}(t) c_{i} e_{i}(t)+\sum_{i=1}^{n} \sum_{j=1}^{n}\left\{\bar{e}_{i}(t) a_{i j}\left[f_{j}\left(w_{j}(t)\right)-f_{j}\left(z_{j}(t)\right)\right]\right. \\
& +e_{i}(t) \bar{a}_{i j}\left[\bar{f}_{j}\left(w_{j}(t)\right)-\bar{f}_{j}\left(z_{j}(t)\right)\right] \\
& +\bar{e}_{i}(t) b_{i j}\left[g_{j}\left(w_{j}(t-\tau)\right)-g_{j}\left(z_{j}(t-\tau)\right)\right] \\
& \left.+e_{i}(t) \bar{b}_{i j}\left[\bar{g}_{j}\left(w_{j}(t-\tau)\right)-\bar{g}_{j}\left(z_{j}(t-\tau)\right)\right]\right\} \\
& -\sum_{i=1}^{n} 2\left[k_{i}^{*} \bar{e}(t) e_{i}(t)+m_{i}{ }^{*} \bar{e}_{i}(t-\tau) e_{i}(t-\tau)\right]
\end{aligned}
$$

According to Lemma 4 and Assumption 1: 


$$
\begin{gathered}
{ }_{0}^{C} D_{t}^{\alpha}\left(V_{1}(t)+V_{2}(t)\right) \leq \quad-\sum_{i=1}^{n} 2 c_{i} \bar{e}_{i}(t) e_{i}(t)+\sum_{i=1}^{n} \sum_{j=1}^{n}\left[\left(a_{i j} \bar{a}_{i j}+l_{j}^{2}\right) \bar{e}_{i}(t) e_{i}(t)+b_{i j} \bar{b}_{i j} \bar{e}_{i}(t) e_{i}(t)\right. \\
\left.\quad+h_{j}^{2} \overline{e_{i}(t-\tau)} e_{i}(t-\tau)\right]-\sum_{i=1}^{n} 2\left[k_{i}^{*} \bar{e}(t) e_{i}(t)-m_{i}{ }^{*} \overline{e_{i}(t-\tau)} e_{i}(t-\tau)\right] \\
=\sum_{i=1}^{n}\left[-2 c_{i}-2 k_{i}^{*}+\sum_{j=1}^{n}\left(a_{i j} \bar{a}_{i j}+l_{j}^{2}+b_{i j} \bar{b}_{i j}\right)\right] \bar{e}_{i}(t) e_{i}(t) \\
\quad+\sum_{i=1}^{n}\left(\sum_{j=1}^{n} h_{j}^{2}-2 m_{i}^{*}\right) \overline{e_{i}(t-\tau)} e_{i}(t-\tau) . \\
\text { Letting } k_{i}^{*}=\frac{1}{2} \sum_{j=1}^{n}\left(a_{i j} \bar{a}_{i j}+l_{j}^{2}+b_{i j} \bar{b}_{i j}\right)-c_{i}+1, m_{i}^{*}=\frac{1}{2} \sum_{j=1}^{n} h_{j}^{2}: \\
{ }_{0}^{C} D_{t}^{\alpha}\left(V_{1}(t)+V_{2}(t)\right) \leq-V_{1}(t) .
\end{gathered}
$$

From Lemma 2 or Lemma 3, one can obtain: $\lim _{t \rightarrow \infty} V_{1}(t)=\lim _{t \rightarrow \infty} e^{H}(t) e(t)=0$, indicating $\lim _{t \rightarrow \infty} e(t)=0$, which shows that systems (9) and (12) can obtain asymptotic synchronization. Meanwhile, according to Remark 1 of Theorem 1 of Ref. [45], the parameter identification is achieved.

Remark 2. Theorem 1 provides a stability criterion for fractional-order nonlinear uncertain systems with time-delay by choosing a Lyapunov function that includes $V_{1}(t)$ and $V_{2}(t)$.

Remark 3. Theorem 1 provides a Lyapunov-based adaptive control method for stability analysis and synchronization of FOCVCNNs.

Remark 4. Lemma 3 is applied to verify the stability of fractional-order with unknown parameters and external disturbances, as well as to the design of synchronous controllers for these systems.

Remark 5. For FOCVCNNs with known parameters, the update laws will be reduced to (14) and (15).

Remark 6. For FOCVCNNs with known parameters and without time-delay, the synchronization between systems (9) and (12) can be achieved under the following control strategy (24).

Remark 7. It is worth mentioning that the synchronization problem discussed in this paper is about fractional-order complex-valued neural networks with time-varying delays and unknown parameters, while most of the existing work on parameter identification methods for synchronization is about fractional-order real-valued models. On the other hand, previous studies have mainly focused on fractional-order complex-valued models with known parameters $[10,31,43]$ or fractional-order complex-valued models without time-delay [46]:

$$
\left\{\begin{array}{l}
u_{i}(t)=-k_{i} e_{i}(t), \\
{ }_{0}^{C} D_{t}^{\alpha} k_{i}=\sigma_{i} \overline{e_{i}(t)} e(t),
\end{array}\right.
$$

where $\sigma_{i}$ is a positive constant.

\section{Numerical Simulations}

In this Section, several numerical examples of fractional-order complex-valued neural networks are given to show the effectiveness of the scheme proposed in previous Sections. For the numerical solution of these systems, the predictor-corrector method [45] of the MATLAB platform is adopted. The Lyapunov exponents of systems are calculated by the algorithm of Wolf et al. [47], with some adaptations. 
Example 1. Consider a class of FOCVCNNs, which is described as follows:

$$
\left\{\begin{array}{l}
{ }_{0}^{C} D_{t}^{\alpha} z_{i}(t)=-c_{i} z_{i}(t)+\sum_{j=1}^{n} a_{i j} f_{j}\left(z_{j}(t)\right)+\sum_{j=1}^{n} b_{i j} g_{j}\left(z_{j}(t-\tau)\right)+I_{i}(t), \\
z_{i}(s)=\varphi_{i}(s), s \in[-\tau, 0], \quad t \geq 0, i=1,2 .
\end{array}\right.
$$

If one selects $\tau=1, a_{11}=2+0.1 i, a_{12}=0.4-0.1 i, a_{21}=5-0.5 i, a_{22}=3-0.2 i$, $b_{11}=-2+0.1 i, b_{12}=0.2+0.1 i, b_{21}=0.3+0.1 i, b_{22}=-2.5-0.3 i, f(z)=g(z)=\tanh (z)$, $I_{1}(t)=I_{2}(t)=0,\left[z_{1}(s), z_{2}(s)\right]^{T}=[0.01+0.01 i, 0.1-0.1 i]^{T}, \forall s \in[-1,0], \alpha=0.96$, then let $\operatorname{Re}\left(a_{11}\right)=1 \sim 2$. Figure 1a depicts the maximum Lyapunov exponent (MLE) spectrum of system (25), and Figure 1b shows its bifurcation diagram. Figure 1 shows that system (25) is chaotic at fractional-order, $\operatorname{Re}\left(a_{11}\right) \in[1.85,2]$.

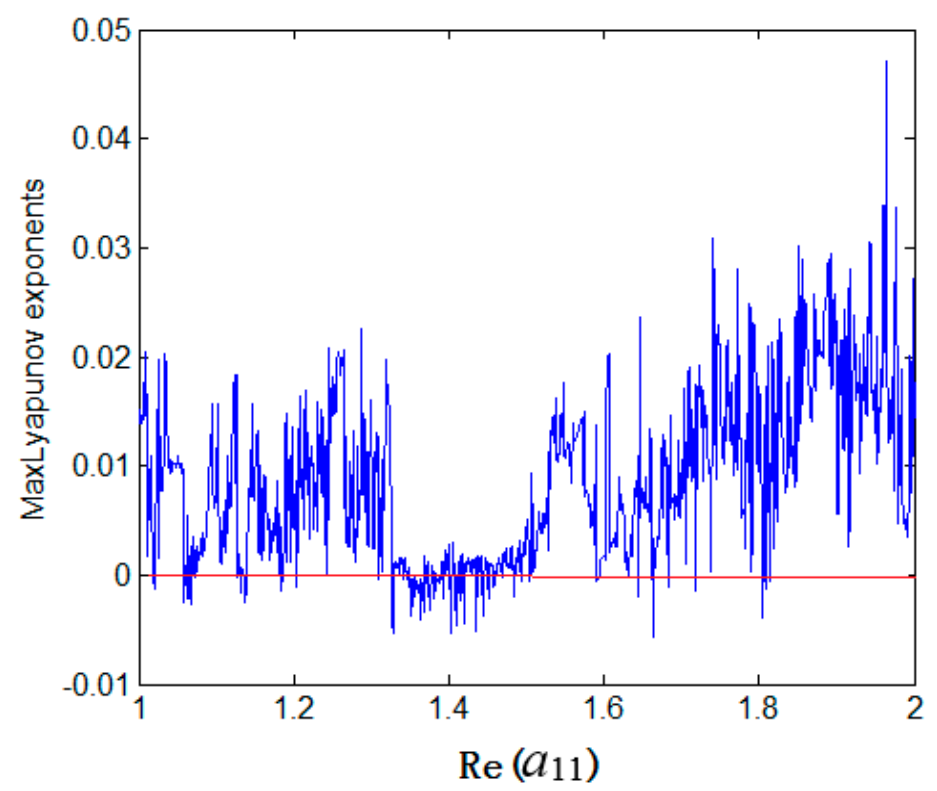

(a)

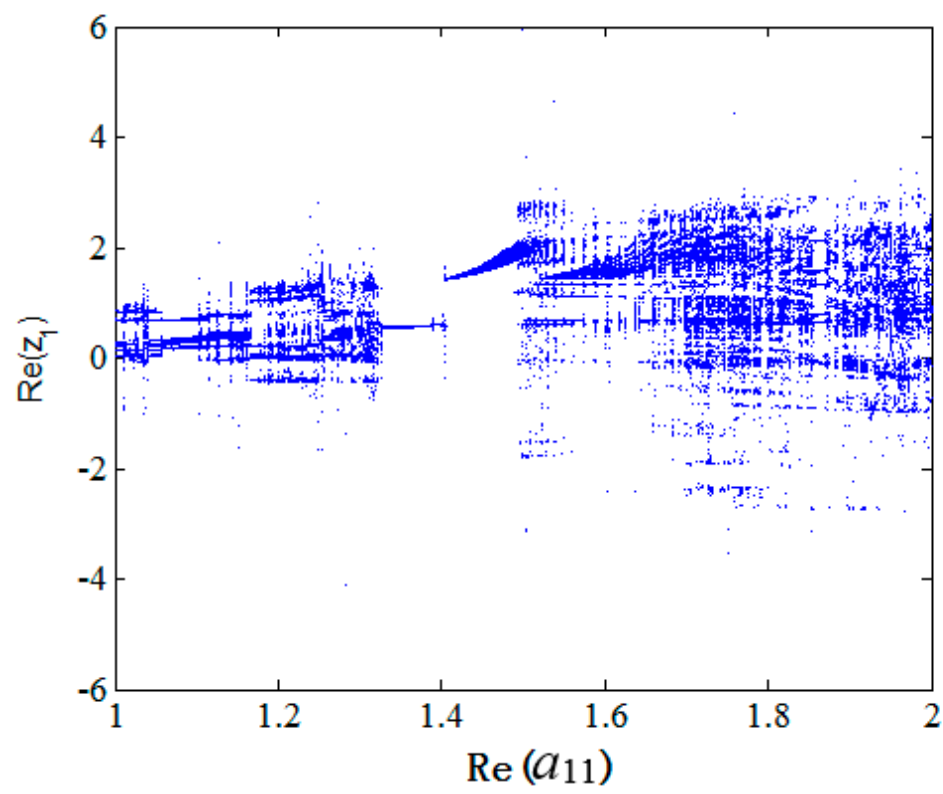

(b)

Figure 1. Dynamic behaviors of fractional-order complex-valued chaotic neural networks (FOCVCNNs) (25) with $\operatorname{Re}\left(a_{11}\right)$ : (a) maximal Lyapunov exponent, (b) bifurcation diagram. 
System (25) can exhibit chaotic behaviors, which can be called fractional-order complexvalued chaotic neural networks. While $a_{11}=2+0.1 i$ and the other parameters are the same as above, the attractor trajectory with the initial condition $\left[z_{1}(s), z_{2}(s)\right]^{T}=[0.1-0.1 i, 0.1]^{T}$ is shown in Figure 2. The state trajectory is shown in Figure 3.

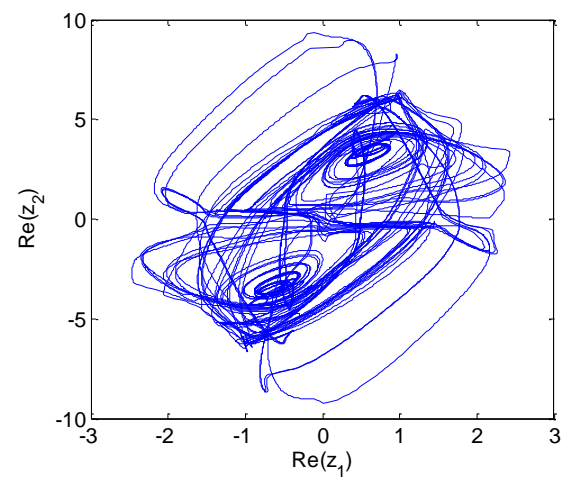

(a)

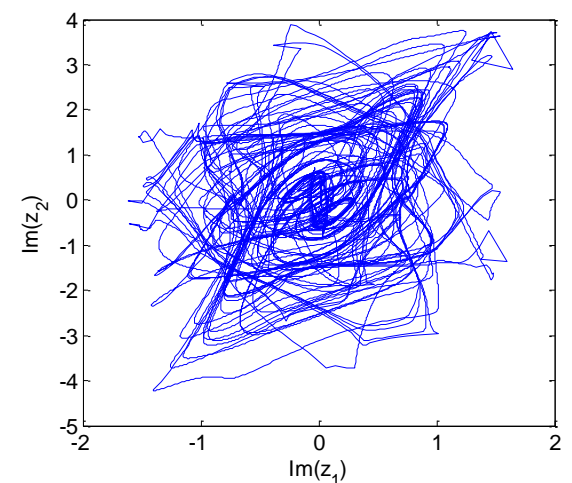

(b)

Figure 2. Chaotic attractors of FOCVCNNs (25) with $\tau=1, a_{11}=2+0.1 i, a_{12}=0.4-0.1 i$, $a_{21}=5-0.5 i, a_{22}=3-0.2 i, b_{11}=-2+0.1 i, b_{12}=0.2+0.1 i, b_{21}=0.3+0.1 i, b_{22}=-2.5-0.3 i$ and fractional-order $\alpha=0.96:(\mathbf{a}) \operatorname{Re}\left(z_{1}\right)$ vs. $\operatorname{Re}\left(z_{2}\right),(\mathbf{b}) \operatorname{Im}\left(z_{1}\right)$ vs. $\operatorname{Im}\left(z_{2}\right)$.
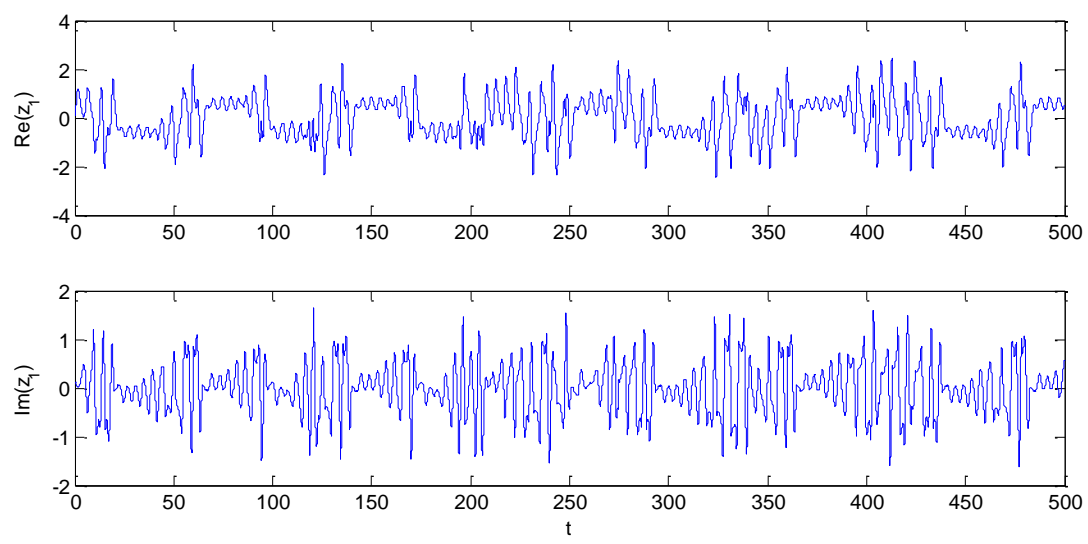

(a)
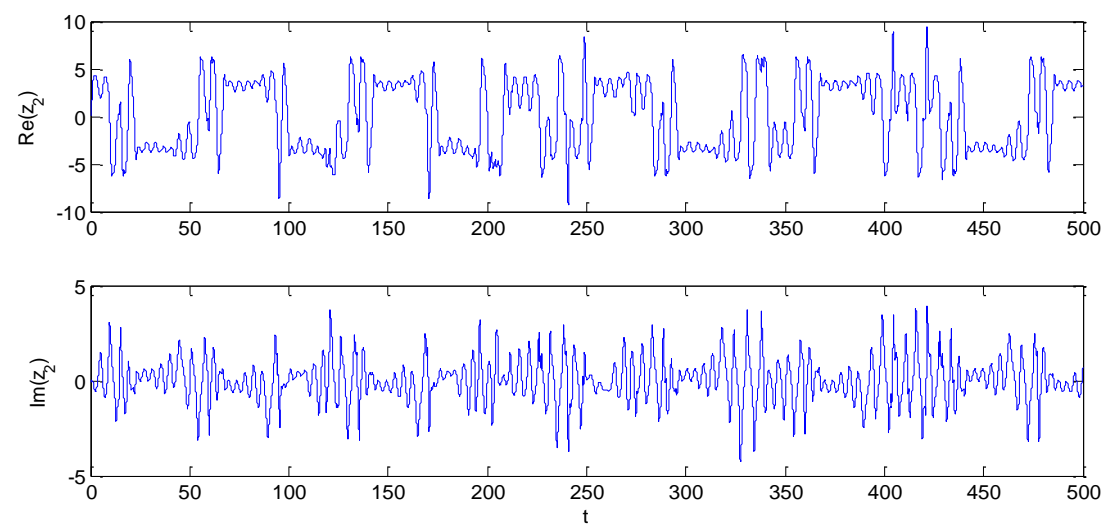

(b)

Figure 3. The state trajectories of FOCVCNNs with $\tau=1, a_{11}=2+0.1 i, a_{12}=0.4-0.1 i$, $a_{21}=5-0.5 i, a_{22}=3-0.2 i, b_{11}=-2+0.1 i, b_{12}=0.2+0.1 i, b_{21}=0.3+0.1 i, b_{22}=-2.5-0.3 i$ and fractional-order $\alpha=0.96, t$ is the time: (a) $\operatorname{Re}\left(z_{1}\right)$ and $\operatorname{Im}\left(z_{1}\right),(\mathbf{b}) \operatorname{Re}\left(z_{2}\right)$ and $\operatorname{Im}\left(z_{2}\right)$. 
Let system (25) be the driving system and assume that the parameters $a_{i j}, b_{i j},(i=1,2$, $j=1,2)$ are unknown, then the response FOCVCNNs are given as follows:

$$
\left\{\begin{array}{l}
{ }_{0}^{C} D_{t}^{\alpha} w_{i}(t)=-c_{i} \boldsymbol{w}_{i}(t)+\sum_{j=1}^{n} \alpha_{i j} f_{j}\left(\boldsymbol{w}_{j}(t)\right)+\sum_{j=1}^{n} \beta_{i j} g_{j}\left(\boldsymbol{w}_{j}(t-\tau)\right)+I_{i}(t)+u_{i}(t), \\
w_{i}(s)=\varphi_{i}(s), s \in[-\tau, 0], \quad t \geq 0, i=1,2
\end{array}\right.
$$

where $\alpha_{i j}, \beta_{i j}$ are estimated values of $a_{i j}, b_{i j}$, respectively and $u_{i}(t)$ are controllers. The controllers and the update laws are selected as Equations (14)-(18). The following initial conditions are chosen:

$$
\alpha_{11}(0)=\alpha_{12}(0)=\alpha_{21}(0)=\alpha_{22}(0)=\beta_{11}(0)=\beta_{12}(0)=\beta_{21}(0)=\beta_{22}(0)=k_{1}(0)=
$$
$k_{2}(0)=0.1, m_{1}(0)=m_{2}(0)=0,\left[w_{1}(s), w_{2}(s)\right]^{T}=[-0.1,0.1 i]^{T}, \forall s \in[-1,0]$ and $\varepsilon_{1}=\varepsilon_{2}=1, \sigma_{1}=\sigma_{2}=10, \eta_{11}=8, \eta_{12}=\eta_{21}=\eta_{22}=\xi_{11}=\xi_{12}=\xi_{21}=\xi_{22}=6$, $\xi_{21}=\xi_{22}=6, I_{1}(t)=I_{2}(t)=0$.

Two FOCVCNNs can achieve synchronization and the parameters are identified, as shown in Figures 4 and 5. Figure 4 shows that the above two pairs of FOCVCNNs achieve asymptotic synchronization through the adaptive controller and adaptive update laws. Figure 5 indicates that all the unknown parameters of the driving system are identified.

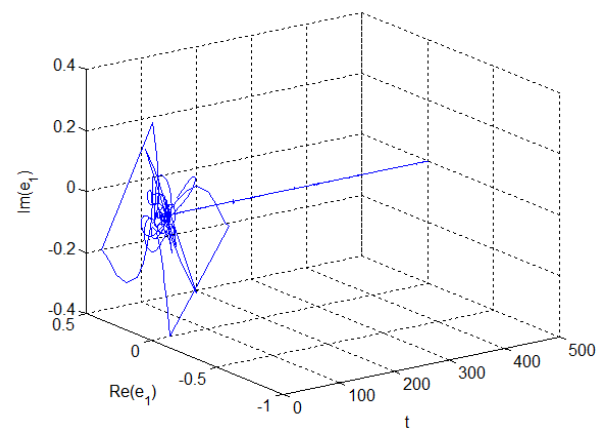

(a)

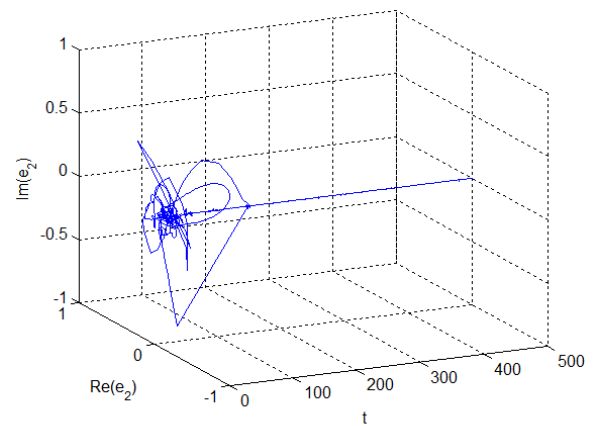

(b)

Figure 4. Synchronization errors of FOCVCNNs (25) and (26): (a) $e_{1}(t)=w_{1}(t)-z_{1}(t)$, (b) $e_{2}(t)=w_{2}(t)-z_{2}(t)$.

It is shown that with this approach one can rapidly achieve global synchronization of these networks, while dynamically identifying all the unknown parameters. Additionally, this method is quite robust against noise effects.

Example 2. To further illustrate the effectiveness and wider application of the proposed scheme, a higher dimensional FOCVNN is considered described by the following equation:

$$
\left\{\begin{array}{l}
{ }_{0}^{C} D_{t}^{\alpha} z_{1}(t)=-z_{1}(t)+a_{11} f\left(z_{1}(t)\right)+a_{12} f\left(z_{2}(t)\right)+a_{13} f\left(z_{3}(t-\tau)\right), \\
{ }_{0}^{C} D_{t}^{\alpha} z_{2}(t)=-z_{2}(t)+a_{21} f\left(z_{1}(t)\right)+a_{22} f\left(z_{2}(t)\right)+a_{23} f\left(z_{3}(t-\tau)\right), \\
{ }_{0}^{C} D_{t}^{\alpha} z_{3}(t)=-z_{3}(t)+a_{31} f\left(z_{1}(t)\right)+a_{32} f\left(z_{2}(t)\right)+a_{33} f\left(z_{3}(t-\tau)\right) .
\end{array}\right.
$$

If $\tau=2$ is selected, then:

$a_{11}=2+0.1 i, a_{12}=16-i, a_{13}=-6+0.5 i, a_{21}=-6+0.5 i, a_{22}=1.6+0.5 i$, $a_{23}=2+0.1 i, a_{31}=-3+0.5 i, a_{32}=4+i, a_{33}=0.2+0.1 i, f\left(z_{i}\right)=\left(\left|z_{i}+1\right|-\left|z_{i}-1\right|\right) / 2$, $i=1,2,3,\left[z_{1}(s), z_{2}(s), z_{3}(s)\right]^{T}=[1+0.1 i, 1-0.1 i,-1+0.1 i]^{T}, \forall s \in[-1,0], \alpha=0.96$, then system (27) can exhibit chaotic behaviors. The attractor trajectory is shown in Figure 6. The state trajectory is shown in Figure 7. 

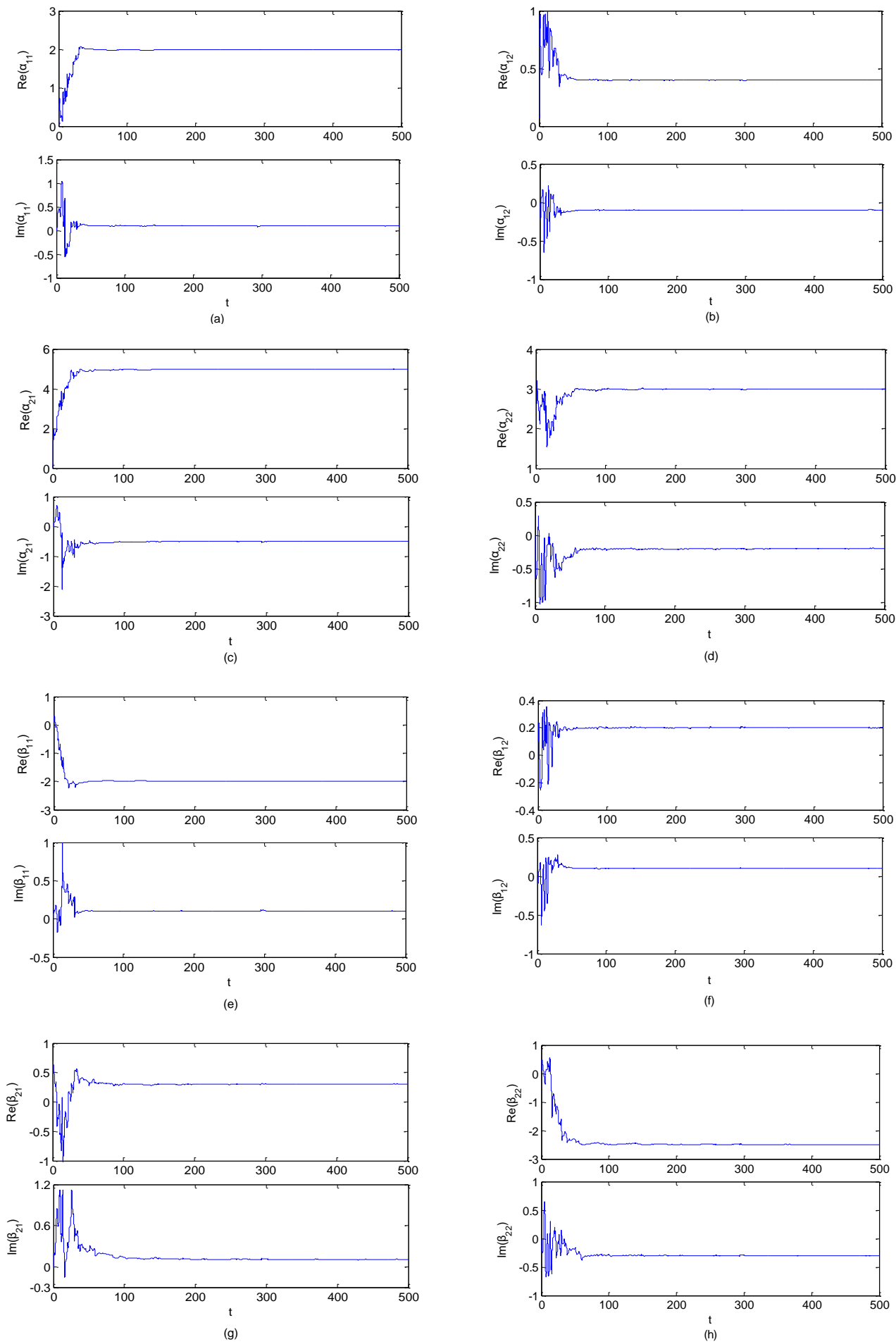

Figure 5. Estimated complex parameters of FOCVCNNs (26): (a) $\alpha_{11} \rightarrow a_{11}=2+0.1 i$, (b) $\quad \alpha_{12} \rightarrow a_{12}=0.4-0.1 i, \quad$ (c) $\quad \alpha_{21} \rightarrow a_{21}=5-0.5 i, \quad$ (d) $\quad \alpha_{22} \rightarrow a_{22}=3-0.2 i$, (e) $\quad \beta_{11} \rightarrow b_{11}=-2+0.1 i, \quad$ (f) $\quad \beta_{12} \rightarrow b_{12}=0.2+0.1 i, \quad$ (g) $\quad \beta_{21} \rightarrow b_{21}=0.3+0.1 i$, (h) $\beta_{22} \rightarrow b_{22}=-2.5-0.3 i$. 


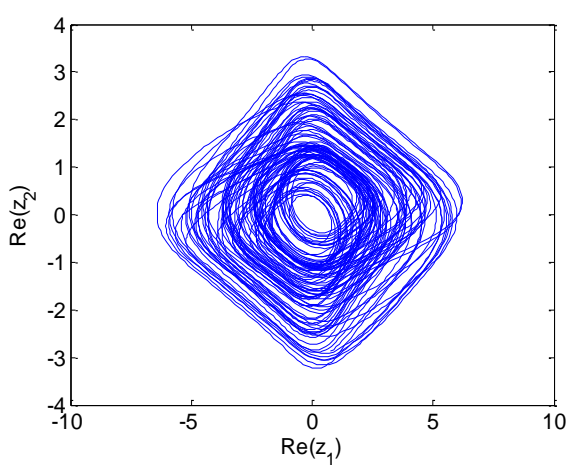

(a)

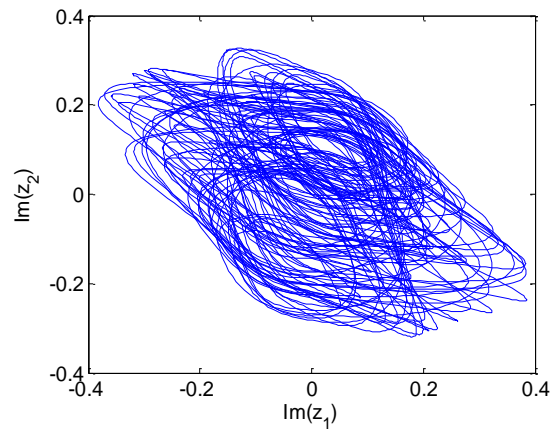

(c)

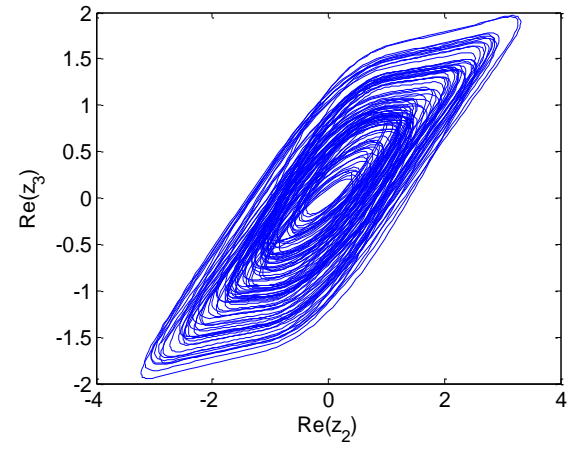

(b)

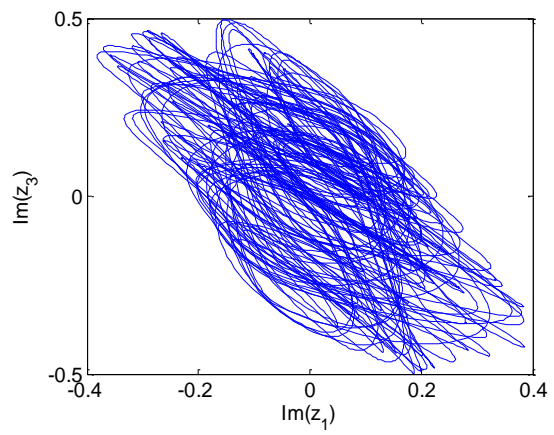

(d)

Figure 6. Chaotic attractors of FOCVCNNs (27): (a) $\operatorname{Re}\left(z_{1}\right)$ vs. $\operatorname{Re}\left(z_{2}\right),(\mathbf{b}) \operatorname{Re}\left(z_{2}\right)$ vs. $\operatorname{Re}\left(z_{3}\right)$, (c) $\operatorname{Im}\left(z_{1}\right)$ vs. $\operatorname{Im}\left(z_{2}\right)$, (d) $\operatorname{Im}\left(z_{1}\right)$ vs. $\operatorname{Im}\left(z_{3}\right)$.

Taking system (27) as the driving system and assuming that the coefficients $a_{i j}(i, j=1,2,3)$ are unknown, the corresponding controlled response system is as follows:

$$
\left\{\begin{array}{l}
{ }_{0}^{C} D_{t}^{\alpha} \boldsymbol{w}_{1}(t)=-\boldsymbol{w}_{1}(t)+b_{11} f\left(\boldsymbol{w}_{1}(t)\right)+b_{12} f\left(\boldsymbol{w}_{2}(t)\right)+b_{13} f\left(\boldsymbol{w}_{3}(t-\tau)\right)+u_{1}(t), \\
{ }_{0}^{C} D_{t}^{\alpha} \boldsymbol{w}_{2}(t)=-\boldsymbol{w}_{2}(t)+b_{21} f\left(\boldsymbol{w}_{1}(t)\right)+b_{22} f\left(\boldsymbol{w}_{2}(t)\right)+b_{23} f\left(\boldsymbol{w}_{3}(t-\tau)\right)+u_{2}(t), \\
{ }_{0}^{C} D_{t}^{\alpha} \boldsymbol{w}_{3}(t)=-\boldsymbol{w}_{3}(t)+b_{31} f\left(\boldsymbol{w}_{1}(t)\right)+b_{32} f\left(\boldsymbol{w}_{2}(t)\right)+b_{33} f\left(\boldsymbol{w}_{3}(t-\tau)\right)+u_{3}(t),
\end{array}\right.
$$

where $b_{i j}(i, j=1,2,3)$ are estimated values of $a_{i j}$ and $u_{i}(t)$ are controllers. Let the system errors be $e_{i}(t)=w_{i}(t)-z_{i}(t),(i=1,2,3)$. The controllers and the update laws are selected as Equations (14)-(18), and the initial conditions are chosen as follows:

$$
\begin{aligned}
& \left(\begin{array}{lll}
b_{11}(0) & b_{12}(0) & b_{13}(0) \\
b_{21}(0) & b_{22}(0) & b_{23}(0) \\
b_{31}(0) & b_{32}(0) & b_{33}(0)
\end{array}\right)=\left(\begin{array}{ccc}
1 & 10-i & -8+i \\
-8+i & 2+i & 2 \\
-3+i & 3+0.5 i & 0.3-0.1 i
\end{array}\right), \\
& \left(\begin{array}{cc}
z_{1}(0) & w_{1}(0) \\
z_{2}(0) & w_{2}(0) \\
z_{3}(0) & w_{3}(0)
\end{array}\right)=\left(\begin{array}{cc}
1 & -1 \\
1 & 2 \\
1 & -1
\end{array}\right), \\
& k_{1}(0)=k_{2}(0)=k_{3}(0)=1 .
\end{aligned}
$$

The simulation results are shown in Figures 8 and 9. Figure 8 shows that two pairs of high-dimensional FOCVCNNs achieve asymptotic synchronization through the adaptive controllers and adaptive update laws. Figure 9 indicates that all the unknown parameters of the driving system (27) are identified. 

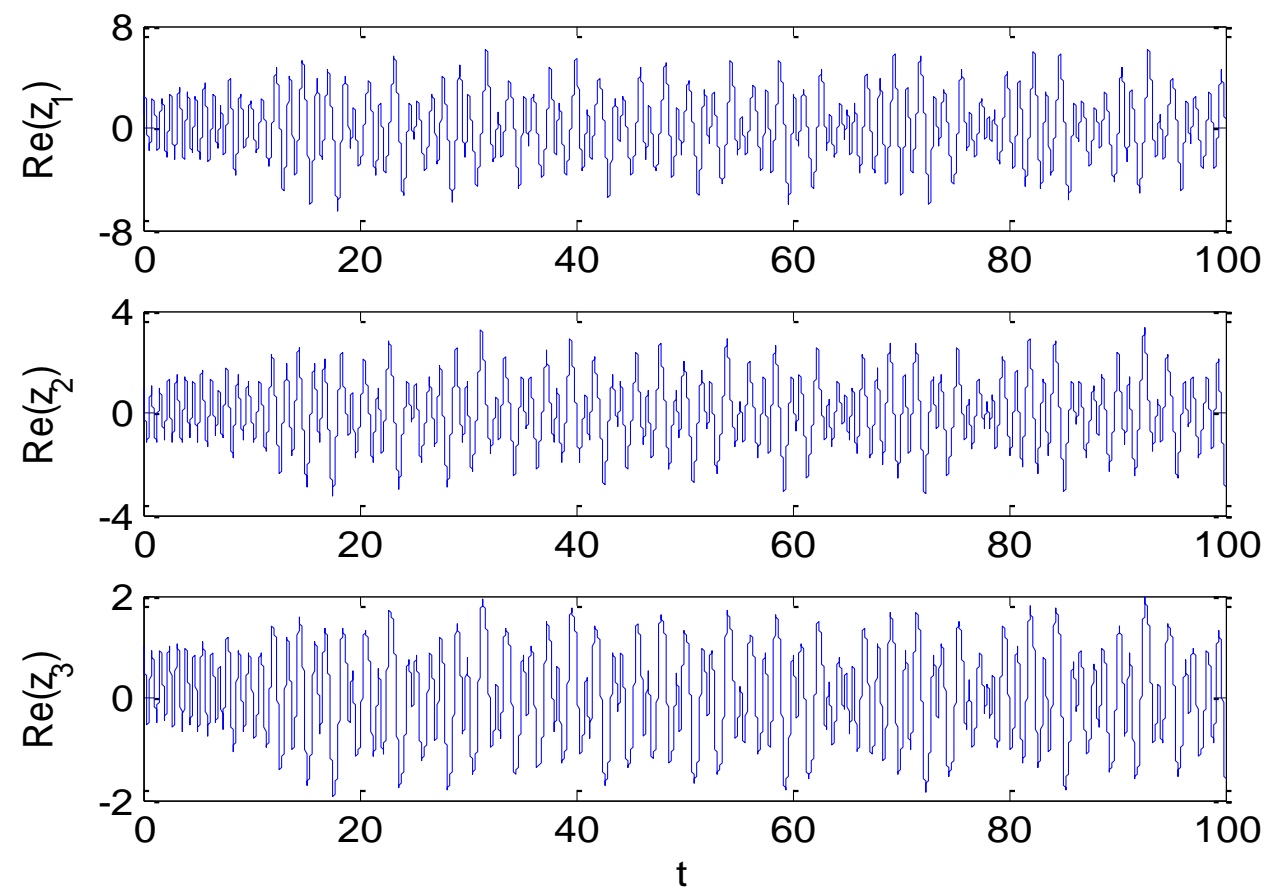

(a)
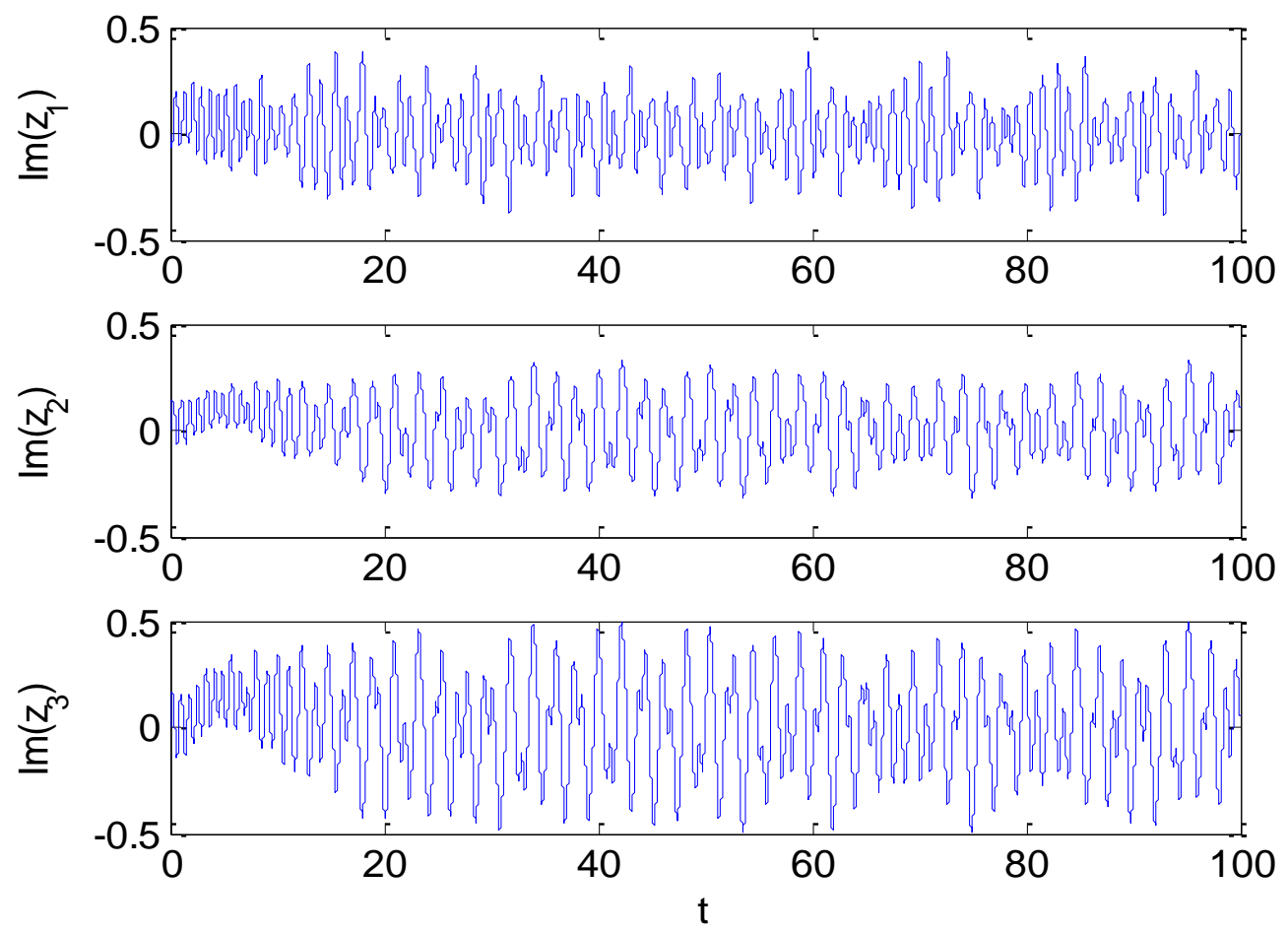

(b)

Figure 7. The state trajectories of FOCVCNNs (27): (a) $\operatorname{Re}\left(z_{1}\right), \operatorname{Re}\left(z_{2}\right)$ and $\operatorname{Re}\left(z_{3}\right)$ vs. $t$, (b) $\operatorname{Im}\left(z_{1}\right), \operatorname{Im}\left(z_{2}\right)$ and $\operatorname{Im}\left(z_{3}\right)$ vs. $t$. 


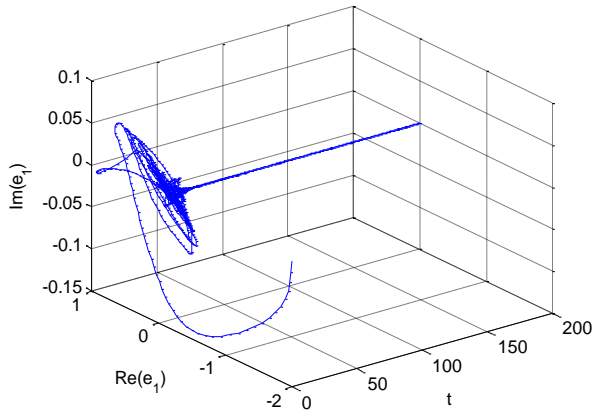

(a)

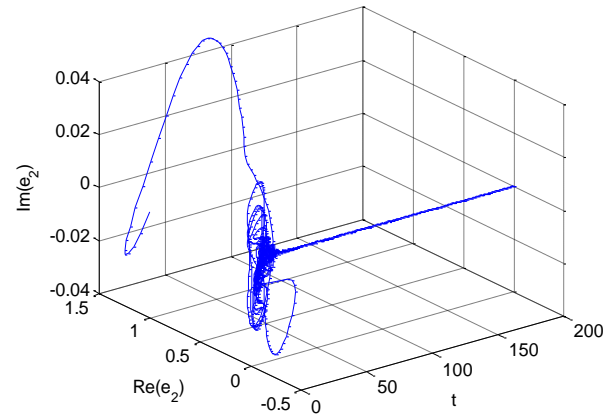

(b)

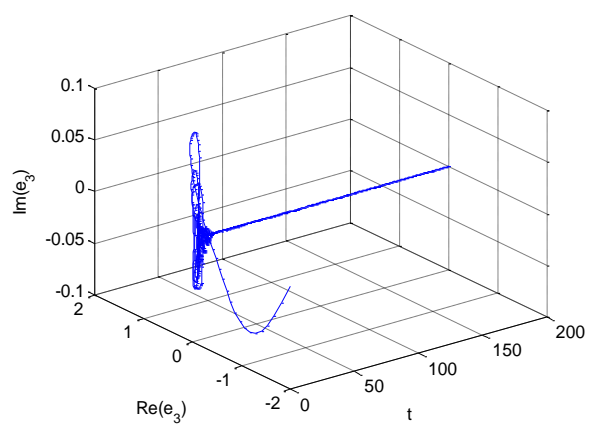

(c)

Figure 8. Synchronization errors of FOCVCNNs (27) and (28): (a) $e_{1}(t)=w_{1}(t)-z_{1}(t),(\mathbf{b}) e_{2}(t)=$ $w_{2}(t)-z_{2}(t),(\mathbf{c}) e_{3}(t)=w_{3}(t)-z_{3}(t)$.

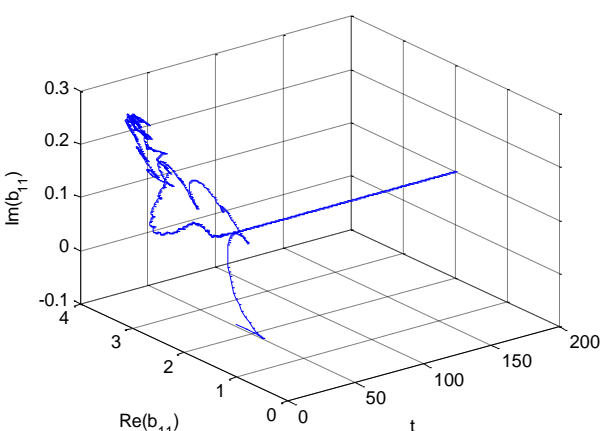

(a)

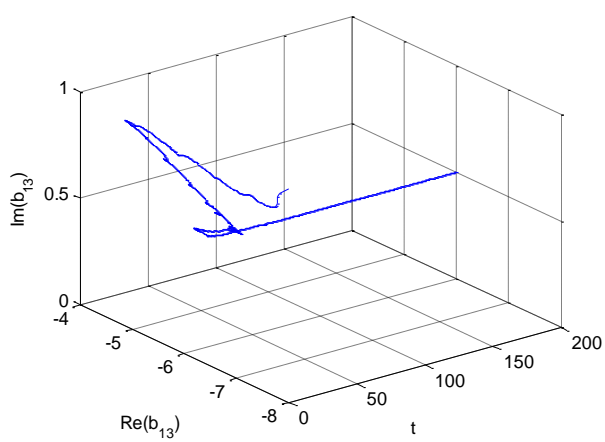

(c)

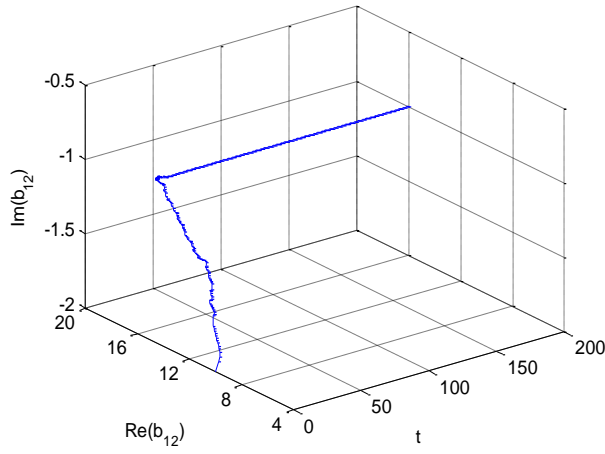

(b)

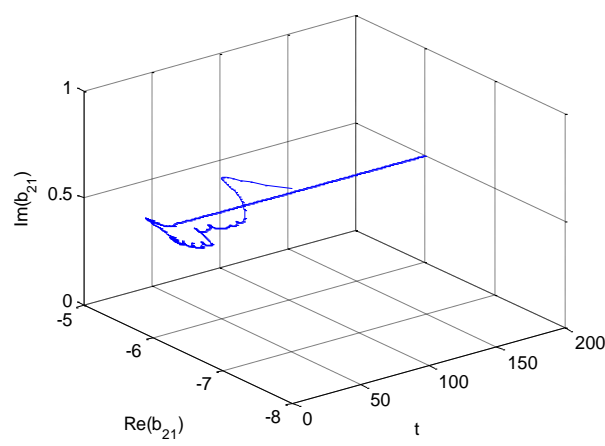

(d)

Figure 9. Estimated complex parameters of FOCVCNNs (28): (a) $b_{11} \rightarrow a_{11}=2+0.1 i$,

(b) $\quad b_{12} \rightarrow a_{12}=16-i$,

(c) $\quad b_{13} \rightarrow a_{13}=-6+0.5 i$,

(d) $\quad b_{21} \rightarrow a_{21}=-6+0.5 i$,

(e) $\quad b_{22} \rightarrow a_{22}=1.6+0.5 i, \quad$ (f) $\quad b_{23} \rightarrow a_{23}=2+0.1 i$,

(g) $\quad b_{31} \rightarrow a_{31}=-3+0.5 i$,

(h) $b_{32} \rightarrow a_{32}=4+i$, (i) $b_{33} \rightarrow a_{33}=0.2+0.1 i$. 


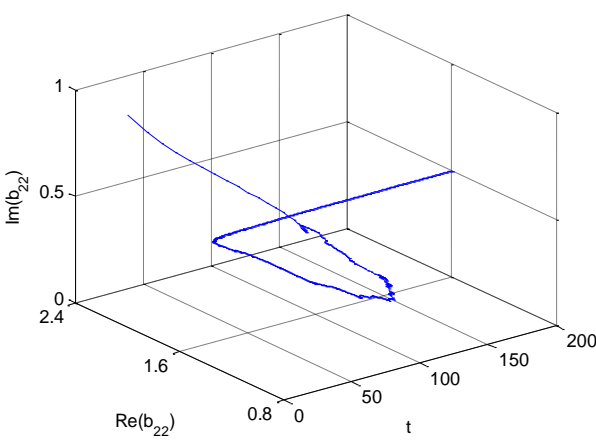

(e)

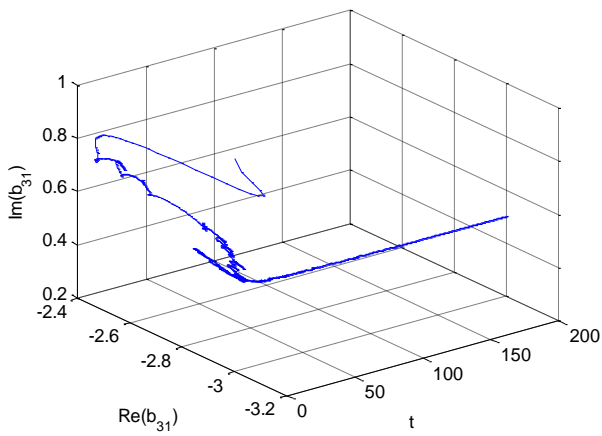

$(\mathrm{g})$

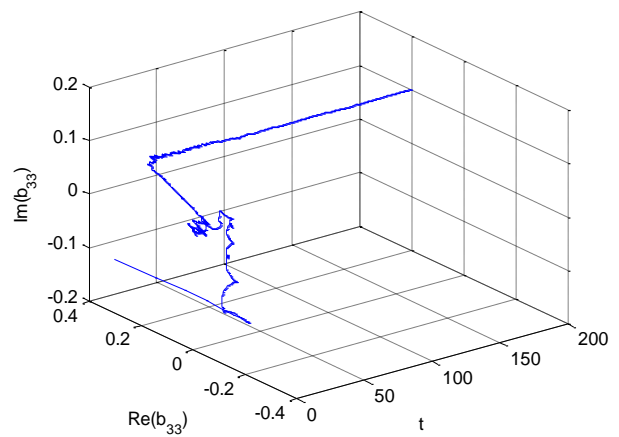

(i)

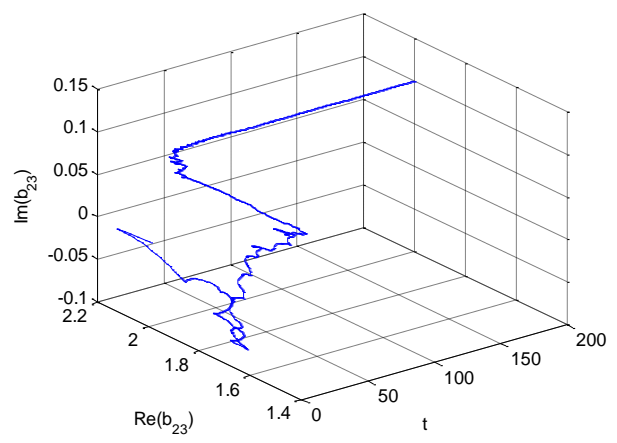

$(\mathbf{f})$

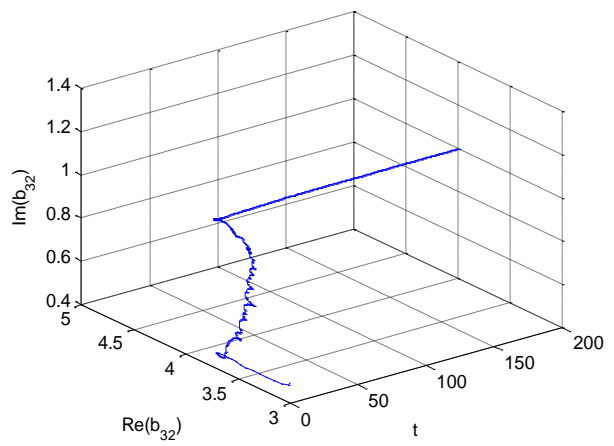

(h)

Figure 9. Cont.

It is not difficult to see from Example 2 that the research results of this paper can be easily extended to the synchronization and parameter identification for high-dimensional FOCVCNNs. Meanwhile, the synchronization control and parameter identification schemes proposed in this paper have very loose conditions, which make them easy to implement in practical applications. In addition, the synchronization control strategies are quite robust to external disturbances.

\section{Conclusions}

This paper focuses on the synchronization and parameter identification of fractionalorder complex-valued chaotic neural networks (FOCVCNNs) with time-delay and unknown complex parameters. Using the complex-valued inequalities of fractional derivatives and stability theory of fractional-order complex-valued systems, the adaptive controllers and complex update laws for synchronizing these systems are proposed. The proposed synchronization scheme preserves the complex nature of FOCVCNNs. Not only a new method for analyzing FOCVCNNs with time-delay and unknown complex parameters is provided here, but also a sensible decrease of the computational and analytical complexity. 
Author Contributions: Conceptualization, M.L.; methodology, R.Z. and M.L.; software, R.Z.; validation, S.Y.; writing-review and editing, M.L. and R.Z.; supervision, S.Y. All authors have read and agreed to the published version of the manuscript.

Funding: The work of S.Y. was supported by the Natural Science Foundation of Hebei province, China (No. A2015205161), and the work of R.Z. was supported by the Science and technology support program of Xingtai, China (No. 2019ZC054).

Conflicts of Interest: The authors declare no conflict of interest.

\section{References}

1. Nitta, T. Orthogonality of decision boundaries of complex-valued neural networks. Neural Comput. 2004, 16, 73-97. [CrossRef]

2. Hirose, A. Complex-Valued Neural Networks: Theories and Applications; World Scientific Publishing Company: Singapore, 2003. [CrossRef]

3. Tanak, G.; Aihara, K. Complex-valued multistate associative memory with nonlinear multilevel functions for gray-level image reconstruction. IEEE Trans. Neural Netw. 2009, 20, 1463-1473. [CrossRef]

4. Amin, M.F.; Murase, K. Single-layered complex-valued neural network for real-valued classification problems. Neurocomputing 2009, 72, 945-955. [CrossRef]

5. Rao, V.S.H.; Murthy, G. Global dynamics of a class of complex valued neural networks. Int. J. Neural Syst. 2008, 18, 165-171.

6. Zhou, W.; Zurada, J.M. Discrete-time recurrent neural networks with complex-valued linear threshold neurons. IEEE Trans. Circuits Syst. II Express Briefs 2009, 56, 669-673. [CrossRef]

7. Duan, C.; Song, Q. Boundedness and stability for discrete-time delayed neural network with complex-valued linear threshold neurons. Discret. Dyn. Nat. Soc. 2010, 19, 368-379. [CrossRef]

8. Bohner, M.; Rao, V.S.H.; Sanyal, S. Global stability of complex-valued neural networks on time scales. Differ. Equ. Dyn. Syst. 2011, 19, 3-11. [CrossRef]

9. Zeng, X.; Li, C.; Huang, T.; He, X. Stability analysis of complex-valued impulsive systems with time delay. Appl. Math. Comput. 2015, 256, 75-82. [CrossRef]

10. Bao, H.; Park, J.H.; Cao, J. Synchronization of fractional-order complex-valued neural networks with time delay. Neural Netw. 2016, 81, 16-28. [CrossRef] [PubMed]

11. Zhou, B.; Song, Q. Boundedness and complete stability of complex-valued neural networks with time delay. IEEE Trans. Neural Netw. Learn. Syst. 2013, 24, 1227-1238. [CrossRef] [PubMed]

12. Huang, Y.; Zhang, H.; Wang, Z. Multistability of complex-valued recurrent neural networks with real-imaginary-type activation functions. Appl. Math. Comput. 2014, 229, 187-200. [CrossRef]

13. Li, L.; Wang, Z.; Li, Y.; Shen, H.; Lu, J. Hopf bifurcation analysis of a complex-valued neural network model with discrete and distributed delays. Appl. Math. Comput. 2018, 330, 152-169. [CrossRef]

14. Zhang, Z.; Lin, C.; Chen, B. Global stability criterion for delayed complex-valued recurrent neural networks. IEEE Trans. Neural Netw. Learn. Syst. 2014, 25, 1704-1708. [CrossRef]

15. Hu, J.; Wang, J. Global stability of complex-valued recurrent neural networks with time-delays. IEEE Trans. Neural Netw. Learn. Syst. 2012, 23, 853-865. [CrossRef] [PubMed]

16. Xu, X.; Zhang, J.; Shi, J. Exponential stability of complex-valued neural networks with mixed delays. Neurocomputing 2014, 128, 483-490. [CrossRef]

17. Wan, P.; Jian, J. Global Mittag-Leffler boundedness for fractional-order complex-valued Cohen-Grossberg neural networks. Neural Process. Lett. 2019, 49, 121-139. [CrossRef]

18. Yang, X.; Li, C.; Huang, T.; Song, Q.; Huang, J. Synchronization of fractional-order memristor-based complex-valued neural networks with uncertain parameters and time delays. Chaos Soliton Fractal 2018, 110, 105-123. [CrossRef]

19. Lee, D.-L., Wang, W.-J. A multivalued bidirectional associative memory operating on a complex domain. Neural Netw. 1998, 11, 1623-1635. [CrossRef]

20. Bao, H.; Cao, J. Projective synchronization of fractional-order memristor-based neural networks. Neural Netw. 2015, 63, 1-9. [CrossRef]

21. Bao, H.; Park, J.; Cao, J. Adaptive synchronization of fractional-order memristor-based neural networks with time delay. Nonlinear Dyn. 2015, 82, 1343-1354. [CrossRef]

22. Chen, J.; Zeng, Z.; Jiang, P. Global Mittag-Leffler stability and synchronization of memristor-based fractional-order neural networks. Neural Netw. 2014, 51, 1-8. [CrossRef]

23. Yang, X.; Li, C.; Song, Q.; Huang, T.; Chen, X. Mittag-Leffler stability analysis on variable-time impulsive fractional-order neural networks. Neurocomputing 2016, 207, 276-286. [CrossRef]

24. Ding, Z.; Shen, Y.; Wang, L. Global Mittag-Leffler synchronization of fractional-order neural networks with discontinuous activations. Neural Netw. 2016, 73, 77-85. [CrossRef] [PubMed]

25. Velmurugana, G.; Rakkiyappana, R.; Vembarasan, V.; Cao, J.; Alsaedi, A. Dissipativity and stability analysis of fractional-order complex-valued neural networks with time delay. Neural Netw. 2016, 86, 42-53. [CrossRef] [PubMed] 
26. Zhang, L.; Song, Q.K.; Zhao, Z.J. Stability analysis of fractional-order complex-valued neural networks with both leakage and discrete delays. Appl. Math. Comput. 2017, 298, 296-309. [CrossRef]

27. Wang, L.; Song, Q.; Liu, Y.; Zhao, Z.; Alsaadi, F.E. Global asymptotic stability of impulsive fractional-order complex-valued neural networks with time delay. Neurocomputing 2017, 243, 49-59. [CrossRef]

28. Rakkiyappan, R.; Velmurugan, G.; Cao, J. Stability analysis of fractional-order complex-valued neural networks with time delays. Chaos Solitons Fractals 2015, 78, 297-316. [CrossRef]

29. Rakkiyappan, R.; Velmurugan, G.; Cao, J. Finite-time stability analysis of fractional-order complex-valued memristor-based neural networks with time delays. Nonlinear Dyn. 2014, 78, 2823-2836. [CrossRef]

30. Chang, W.; Zhu, S.; Li, J.; Sun, K. Global Mittag-Leffler stabilization of fractional-order complex-valued memristive neural networks. Appl. Math. Comput. 2018, 338, 346-362. [CrossRef]

31. Zhang, Y.; Deng, S. Finite-time projective synchronization of fractional-order complex-valued memristor-based neural networks with delay. Chaos Solitons Fractals 2019, 128, 176-190. [CrossRef]

32. Li, L.; Wang, Z.; Lu, J.; Li, Y. Adaptive Synchronization of Fractional-Order Complex-Valued Neural Networks with Discrete and Distributed Delays. Entropy 2018, 20, 124. [CrossRef] [PubMed]

33. Niamsup, P.; Botmart, T.; Weera, W. Modified function projective synchronization of complex dynamical networks with mixed time-varying and asymmetric coupling delays via new hybrid pinning adaptive control. Adv. Differ. Equ. 2017, 1, 1-31. [CrossRef]

34. Chartbupapan, W.; Bagdasar, O.; Mukdasai, K. A novel delay-dependent asymptotic stability conditions for differential and Riemann-Liouville fractional differential neutral systems with constant delays and nonlinear perturbation. Mathematics 2020, 8 , 82. [CrossRef]

35. Dai, X.; Li, X.; Gutiérreze, R.; Guo, H. Explosive synchronization in populations of cooperative and competitive oscillators. Chaos Solitons Fractals 2020, 132, 109589. [CrossRef]

36. Dai, X.; Li, X.; Jia, D.; Perc, M.; Manshour, P.; Wang, Z.; Boccaletti, S. Discontinuous Transitions and Rhythmic States in the D-Dimensional Kuramoto Model Induced by a Positive Feedback with the Global Order Parameter. Phys. Rev. Lett. 2020, 125, 194101. [CrossRef]

37. Arslan, E.; Narayanan, G.; Ali, M.S.; Arik, S.; Saroha, M. Controller design for finite-time and fixed-time stabilization of fractionalorder memristive complex-valued BAM neural networks with uncertain parameters and time-varying delays. Neural Netw. 2020, 130, 60-74. [CrossRef] [PubMed]

38. Zhang, R.X.; Liu, Y.L. A new Barbalat's lemma and Lyapunov stability theorem for fractional order systems. In Proceedings of the 29th Chinese control and decision conference (CCDC), Chongqing, China, 28-30 May 2017; pp. 3676-3681.

39. Zhang, R.X.; Liu, Y.L.; Yang, S.P. Adaptive synchronization of fractional-order complex chaotic system with unknown complex parameters. Entropy 2019, 21, 207. [CrossRef]

40. Zhang, R.X.; Feng, S.W.; Yang, S.P. Complex Modified Projective Synchronization of Fractional-order Complex-Variable Chaotic System with Unknown Complex Parameters. Entropy 2019, 21, 407. [CrossRef]

41. Podlubny, I. Fractional Differential Equations; Academic Press: San Diego, CA, USA, 1999. Available online: https://www. sciencedirect.com/bookseries/mathematics-in-science-and-engineering/vol/198/suppl/C (accessed on 6 October 2021).

42. Quan, X.; Zhuang, S.; Liu, S.; Xiao, J. Decentralized adaptive coupling synchronization of fractional-order complex-variable dynamical networks. Neurocomputing 2016, 186C, 119-126. [CrossRef]

43. Li, H.L.; Hu, C.; Cao, J.D. Quasi-projective and complete synchronization of fractional-order complex-valued neural networks with time delays. Neural Netw. 2019, 118, 102-109. [CrossRef]

44. Wu, Z.Y.; Chen, G.R.; Fu, X.C. Synchronization of a network coupled with complex-variable chaotic systems. Chaos Interdiscip. J. Nonlinear Sci. 2012, 22, 023127. [CrossRef] [PubMed]

45. Kai, D.; Ford, D.J.; Freed, A.D. A predictor-corrector approach for the numerical solution of fractional differential equations. Nonlinear Dyn. 2002, 29, 3-22. [CrossRef]

46. Gu, Y.; Yu, Y.; Wang, H. Synchronization-based parameter estimation of fractional-order neural networks. Phys. A Stat. Mech. Appl. 2017, 483, 351-361. [CrossRef]

47. Wolf, A.; Swift, J.B.; Swinney, H.L.; Vastano, J.A. Determining Lyapunov exponents from a time series. Phys. D Nonlinear Phenom. 1985, 16, 285-317. [CrossRef] 